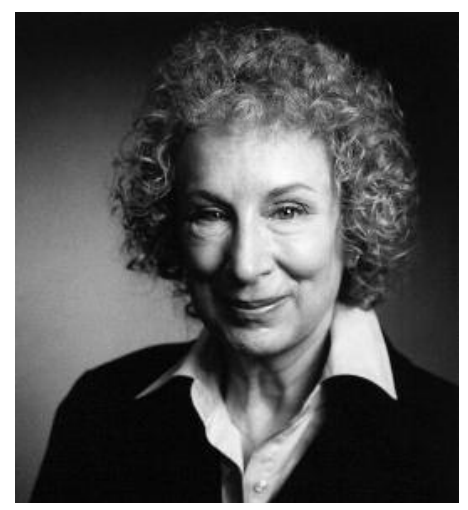

Margaret ATWOOD nació en Ottawa en 1939. Es una de las autoras más importantes de Canadá, y también una de las más premiadas. Cursó estudios en las universidades de Toronto, el Radcliffe College y Harvard. Su primer libro de poesía, Double Persephone, se publicó en 1961. Fue profesora de Literatura inglesa en diversas universidades canadienses (1964-1972) y lectora en la Universidad de Toronto (1972-1973). Ganó reconocimiento con The Edible Woman (1969), Resurgir (1972), Lady Oracle (1976), Life Before Man (1979) y Ojo de gato (1989). Autora de más de veinte libros de novelas, cuentos, poesía y crítica literaria, ha sido galardonada con numerosos premios. Su novela The Robber Bride (1993) fue coganadora del Premio Trillium en 1994. El conjunto de su obra fue premiado con el Premio Internacional del Welsh Arts Council's (1982). Ha residido en Boston, Vancouver, Edmonton, Montreal, Berlín, Edimburgo, Londres y el sur de Francia. Sus últimas obras traducidas al castellano son: El asesino ciego (2000), Penélope y las doce criadas (2005), La maldición de Eva (2006) y Érase una vez (2007). 


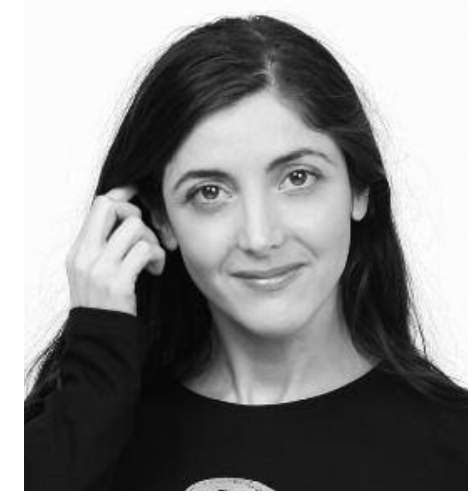

ESPIDO Freire (Bilbao, 1974) es licenciada en Filología Inglesa por la Universidad de Deusto. Entre sus novelas publicadas cabe citar Irlanda (1998), Donde siempre es Octubre (1999) y Melocotones Helados (Premio Planeta de Novela, 1999). Es también autora de los ensayos Primer Amor (2000), Cuando comer es un infierno (2002), Querida Jane, querida Charlotte (2004), y de las novelas Diabulus in musica (2001), Nos espera la noche (2003), La diosa del pubis azul (junto a Raúl del Pozo, 2005) y Soria Moria (Premio Ateneo de Sevilla, 2005). Ha cultivado el relato y el cuento, y su primer libro de poemas es Aland la blanca (2001).

Colaboradora en prensa (El País, La Razón, El Mundo), radio (Onda Cero) y televisión (Antena 3), pasó de participar activamente en talleres literarios a interesarse por la pedagogía de la creación, impartiendo cursos de creación literaria en diversas universidades españolas e internacionales (en la actualidad hay varios cursos en marcha en Toledo, Ávila y La Coruña).

La crítica la ha saludado como a una de las voces más interesantes de la narrativa española, y las alabanzas que surgieron con su primera obra han acompañado a las siguientes. Sus libros se han traducido al francés, alemán, portugués, griego, polaco, holandés, italiano y turco, y su novela Irlanda recibió en 1999 el premio francés Millepage, que los libreros conceden a la novela revelación extranjera. En mayo del 2000 recibió el Premio Qué Leer a la mejor novela española. En 2006 ha aparecido su última obra, el ensayo Mileuristas.

$\Rightarrow$ www.espidofreire.com 


\title{
MARGARET ATWOOD: \\ LA SIRENA DE GÉNEROS
}

\author{
ESPIDO FREIRE \\ www.espidofreire.com
}

\begin{abstract}
RESUMEN
En la narrativa de Margaret Atwood la sorpresa, el uso poético del lenguaje y la reconstrucción constante de la identidad de los personajes guían al lector a traves de los distintos textos. Tanto en la reconstrucción de Los diarios de Susanna Moodie como en la traducción de emociones y sentimientos de la reina de Dinamarca en «La respuesta de Getrudis», la figura de las protagonistas femeninas fuertes e imprevisibles reinventan el misterio del eterno femenino. Las criadas y las señoras, desde sus peculiares puntos de vista, definen la sociedad con distancia y escepticismo, sabedoras de que son más de lo que el otro (el lector o los personajes) pueden atisbar. En un acto lúdico constante, la literatura se convierte en un juego eterno, con las palabras como reglas.

$\Rightarrow$ Palabras Clave: M. Atwood, personaje femenino, Canadá, juego, literatura.
\end{abstract}

Con Margaret Atwood nunca se sabe.

Como si, tras la liebre blanca, nos hubiéramos introducido en un universo paralelo, en una realidad con normas crueles y propias, sus personajes poseen una consistencia especial, una densidad mucho más pesada, que hace que caminen por la historia como si fueran seres normales. Si al kilo de plomo le brindáramos la apariencia de cien gramos de pluma, daríamos con la fórmula alquímica que les permite ser al mismo tiempo gráciles e inamovibles, serenos y atroces.

Resulta terrible que sus novelas acaben, porque ese hermoso espejo se diluye: pero algo aún más horrendo llega con la relectura y la compresión real de esa obra. Nadie puede escapar de Atwood, porque sus personajes han renunciado a la mentira, y no ofrecen ni 
siquiera el consuelo del autoengaño. Eso buscábamos, la verdad, esa obscena obsesión de los lectores por la verdad. Luego, cuando la obtenemos, qué terrible error ha sido morder la manzana, qué exilio tan duro nos espera.

Los poetas, por regla general, no cuentan historias. Eso nos permite refugiarnos en lo subjetivo: el poema se convierte en algo inofensivo porque ellos piensan, ellos sienten esos versos. Podemos apropiarnos de la obra o no, pero sus ideas, mucho más terribles que los sustantivos y su orden, continúan flotando, inmóviles en la voluntad de la incomprensión. Atwood decidió en algún momento entregar sus dones al servicio del mal, es decir, de la prosa, cotidiana, inteligible, inmediata y retorcida aliada. Se mueve entre los dos géneros como una sirena con voz y con piernas, pero como las sirenas, en cada uno de ellos añora lo que no encuentra, y lo importa a través de pequeños trucos.

No adopta el aspecto de las sirenas de mar, de largos cabellos rubios y ojos soñadores y turbios. Los rizos de Atwood se rebelan contra cualquier sujeción, y la mirada, desde cualquier fotografía, en las entrevistas más superficiales, no pierden una curiosidad punzante, incómoda. Tiene algo de bruja que rompe la burbuja de un sueño, de esclavo que susurra al vencedor, bajo la corona de laurel, que no debe olvidar que es mortal, de niño que grita que el emperador está desnudo.

No había ninguna necesidad, por ejemplo, de rescatar los textos de Susanna Moodie. Se habían convertido ya en un clásico, una lucha diaria entre la tenacidad y la naturaleza, una descripción de cómo la naturaleza canadiense podía convertir a quien la observara, y después, por la espalda, hundir un puñal en su espalda. Susanna Moodie, desde sus palabras algo alambicadas, pero con- 
servada con el respeto y la nariz torcida que merece algo conservado en formol, hablaba de su esfuerzo británico por comprender qué acechaba en los bosques del Nuevo Mundo, de los indios y la caza, de su horror por la esclavitud, y su loza inglesa cuidadosamente preservada en cajas de paja, a la espera de un té con los notables de la localidad.

Nada más se le podía pedir: había cumplido de sobra su papel. Bien educada, incluso un poco demasiado liberal para su época y país, escritora en un mundo en el que no debía serlo, en una época en la que las hermanas Brontë daban a la imprenta novelas ocultas bajo nombres falsos, ¿qué podía decirse de Susanna Moodie, salvo una alabanza, un tenue silbido de admiración ante su valor y su coraje?

Nunca se sabe con Margaret Atwood. Ella se enfrentó a la ilustre pionera y le levantó las faldas. Si Moodie escribió en prosa, ella le respondió en verso, y revolvió con saña una puñal en cada herida que adivinó. Allí, ocultas bajo el civilizado narrar de los hechos, se encontraban las debilidades y las flaquezas de Susanna Moodie: el dolor tras perder a su hijo ahogado, el espanto hacia lo desconocido, aquel bosque impenetrable que no se parecía a ningún otro, salvo en sus pesadillas, el miedo a los incendios. En Los diarios de Susanna Moodie, Atwood revela una mujer mucho más interesante que la de los textos que los escolares canadienses estudian cada año, desconcertada y valiente muy a su pesar.

Que la muerte y la distancia nos libren de caer bajo el ojo claro, de cazador tras la liebre, auque sea blanca y lleve a otro mundo, de Margaret Atwood. Como los monstruos mitológicos, nadie puede acabar con ella hasta que desvele su enigma, y éste dista mucho de ser descubierto. 
Salta, por ejemplo, hasta los versos de Shakespeare, y, aburrida, decide volcarlos en prosa. En «La respuesta de Gertrudis» (Gertrude talks back) la reina de Dinamarca se muestra a salvo del tóxico encanto que su hijo Hamlet ha esparcido por toda la corte. Adorado, mimado, hijo único, convencido como todo heredero de que un gesto suyo puede detener cielo y tierra, Hamlet acusa a su madre de sus pecados, de sus vicios, de haber buscado demasiado pronto a un hombre que meter en su cama. Shakespeare, asomado tras su capa negra, asiente, tan seducido como el resto de los cortesanos, y deja a Gertrudis temblorosa y sumisa, tras la durísima conversación en su cuarto, que finaliza con Polonio muerto y la absoluta claudicación de la reina.

Gertrudis, cuando es Atwood quien le permite hablar, mira con serenidad a su hijo. Lo conoce bien, y sabe de qué mañas es capaz, con tal de salirse con la suya. Hamlet gritará todo lo que desee. Ella lo tiene por un niño impulsivo, egoísta, que no merece más que una mano firme hasta que se le pase el berrinche. Cuando él clama que debe mirarse en el espejo, para ver su auténtico rostro, ella contesta, impasible: «deja de liar con mi espejo, Hamlet. Sería el tercero que me rompieras».

¿Amó esta Gertrudis a su esposo? Es posible, pero tal cosa es asunto suyo. Lo cierto es que ahora, clame Hamlet lo que desee, prefiere a Claudio, y no hay más vueltas que darle. El mundo hubiera perdido una tragedia, y Dinamarca conservado unos cuantos nobles ciudadanos, si la actitud de Gertrudis hubiera sido la que Atwood defiende: hijo, está todo en orden, te guste o no. No has venido a enderezar nada. Déjanos en paz. "Madre, no te retuerzas así las manos». «No me retuerzo las manos, me estoy secando las uñas». 
Atwood no deja en paz el pasado, pero tampoco piensa admitir el futuro sin luchar. Sus novelas de ciencia ficción hablan con esa misma seguridad abrumadora de un mundo en el que sólo el sentido común puede vencer el absurdo de permanecer vivos. En El cuento de la criada, se balancea traviesa sobre los miedos contemporáneos y nos reta a un $y$ si.

¿Y si, definitivamente, las máscaras desaparecieran, y se revelara que el único valor que la sociedad encuentra a las mujeres es su capacidad para reproducirse? ¿Y si se hablara claro, y se prohibiera a las jóvenes que leyeran, que escribiera, que mostraran su cuerpo? Caminarían entonces custodiadas bajo largos velos rojos, indicada su fertilidad por un código. ¿Y si?

Todas las fábulas se convierten en realidad por un giro casual, algo que no debería haber ocurrido, y de pronto sucede. Cuando Atwood habla de las criadas embarazadas, silenciosas y veladas, las Torres Gemelas permanecían intactas, y los burka no dejaban de ser una realidad horrenda, pero lejana. Entonces, de nuevo, como una oscilación sobre las aguas de lago, que algunos llamarían sombra, y otros Nessie, Margaret Atwood se escapa y salta a otra realidad.

En Alias Grace habla de otra criada, Grace Marks, condenada en 1848 por haber asesinado a sus señores. Una abominación, dijeron entonces, porque los libros de historia también recogen ese hecho, un toque de atención para aquellos que dejaban sus vidas en manos de los sirvientes, y olvidaban la pobreza, la desesperación y el hambre que éstos atravesaban. Grace no es buena, ni mala. No del todo, al menos. Quien la observa, y quien nos transmite a través de sus ojos su concepto del mundo, no sabe si ha sido asesina o instrumento, una perversa seductora o una joven demasiado asustada para huir. Tampoco el lector tiene del todo claro qué versión le gus- 
taría más que fuera la verdadera. De hecho, sospecha que prefiere la mentira, pese a lo que en el propio texto se deja claro: que buscamos, ingenuos cazadores de historias, la verdad. Con Margaret Atwood nunca se sabe.

¿Qué le interesa a ella? Los niños, parece claro. Las niñas claras y malignas, que ejercen el control sobre las que son buenas, algo lentas, algo bobonas. Los animales, como corresponde a la hija de un zoólogo, que ha visto qué guardan los mamíferos bajo la piel y los prefiere intactos. Los seres humanos, a los que disecciona, en cambio, como si la piel estorbara y nublara el mecanismo palpitante que les hace moverse. Las mujeres, a las que trata sin compasión ni idealizaciones, como temas poco explorados, terra incognita, y por lo tanto, propensa a ser mitificada.

No parece ser el dinero lo que la mueve: cuando obtuvo el Premio Booker, lo donó integramente a grupos que lucharan por el medio ambiente (los bosques canadienses, espesos y enzarzados en murmullos, las criaturas aún no descubiertas que lo protegen); ni la fama, ya que pocos premios le quedan por conseguir.

Habla como hablaba Casandra en Troya, porque ésa es su obligación, y porque sería un pecado desperdiciar el don otorgado por los dioses. Pero, como a la profetisa griega, nadie la cree hasta que resulta demasiado tarde. Entonces, confusos, alzan los ojos hacia ella, y dicen, ah, era eso, a eso te referías, de eso advertían tus palabras...

A veces dice la verdad, y otras no. Era sólo un juego, parece indicar, entre sus versos. Tranquilos, sólo son mentiras... ¿Qué estúpido se tomaría la literatura en serio?

No se sabe. 